\title{
The survey and research of deep geology to Jiaodong Area in Shandong - Preliminary result of MT exploration
}

\author{
Yan Jiayong, Kun Zhang ${ }^{*}$, Hao Hu, Lusen Shao, Guangming Fu \\ Institute of Mineral Resources Chinese Academy of Geological Sciences, MLR Key Laboratory of Metallogeny and Mineral Assessment \\ Beijing, China \\ yanjy@163.com
}

\begin{abstract}
Jiaodong area is the most important gold concentration area in China with huge prospecting potential in deep portion. Magnetotelluric(MT) has some advantages of great exploration depth, high resolution and low cost, so we arrange MT exploration in Jiaodong area with less previous work for the deep structure study in electrical models. Then we discuss the main geology and ore control structure based on the electrical model.
\end{abstract}

\section{Keywords—magnetotelluric; Jiaodong; deep geology}

\section{INTRODUCTION}

Jiaodong gold deposits are mainly concentrated in the north and east of Shandong Peninsula, and across the North China plate and Qinling - Dabie- Sulu orogenic belt.It is limited by the Taocun- Doushan,Guocheng- Jimo and Jiaozho Bay Shanxiangjia - Haoguanzhuang faults.Jiaobei arch is one of the main ore - bearing area, which located in the eastern part of the orogenic belt, and is the main component of the ancient metamorphic basement in Jiaodong .

Jiaodong area is the most important gold concentration area in China with favorable metallogenic conditions, and is mainly consisted of fractured altered and quartz vein gold deposit, mainly including Zhao (yuan) - Ping (du), Jiaojia and Sanshan dao metallogenic belt ${ }^{[1]}$. But the exploration depth is less than $1000 \mathrm{~m}$ in the area, so the deep prospecting potential is huge ${ }^{[4]}$.

Geophysical deep exploration is a important mean in the study of deep control factors of mineralization and ore ${ }^{[2]}$, and MT exploration method has some advantages of great exploration depth, high resolution and low cost ${ }^{[3]}$.Considering the less previous work in Jiaodong area, we design two profiles of MT (completed stations are shown in Figure 1) to obtain the deep electrical structure of the area.

\section{MT FIELD EXPLORATION}

\section{A. Selecting a Template}

To address the shortcomings of previous work, broadband MT data was subsequently collected in 2015 at 107 stations on the two lines in Jiaodong area (shown in Fig. 1) using interstation spacing $1-5 \mathrm{~km}$. The direction of two profiles is NWW - SEE. Time-series data (typically spanning more than
$12 \mathrm{~h}$ ) were converted into frequency domain estimates of impedances and transfer functions, also using the robust, multivariate processing algorithm of Egbert and a crossreferencing technique using the data processing software kit, which in most cases resulted in smooth response curves over the frequency range $0.01-320 \mathrm{~Hz}$.

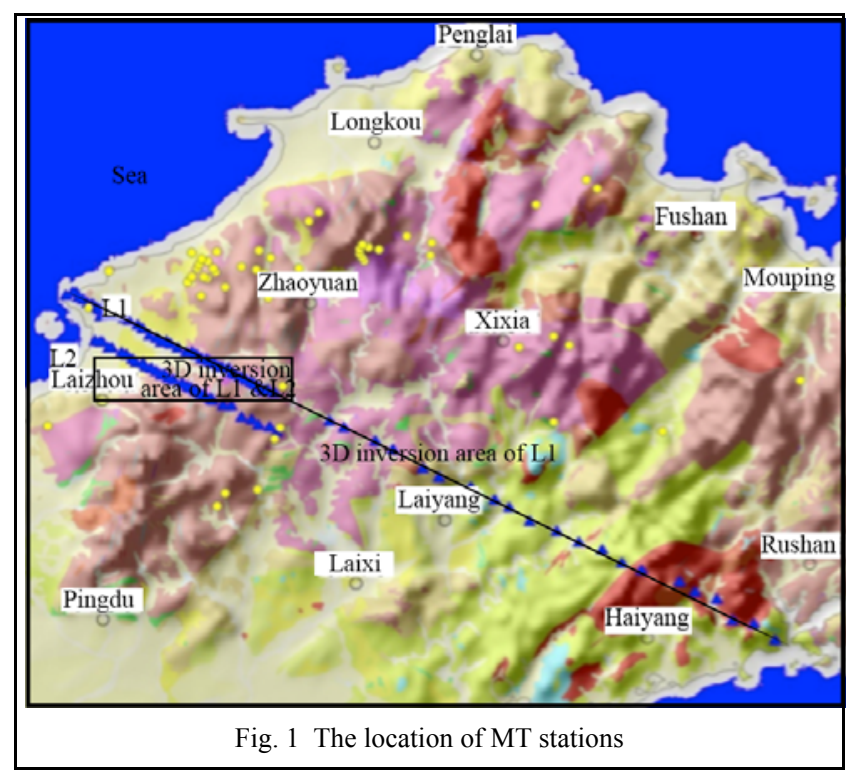

\section{3D INVERSION OF MT DATA}

Despite the presence of a flying spot and weak static shift in the apparent resistivity data, spatial maps of apparent resistivity and phases generally behaved well and exhibited coherent features. De-noising (Zhang, 2012a) and 3D automatic static shift correction methods (Zhang et al, 2015) were used to correct the data automatically. Then the quality of the real data is good enough for $2 \mathrm{D}$ and $3 \mathrm{D}$ inversion.

The MT data was inverted using the 3D nonlinear conjugate gradient inversion program of Zhang (Zhang, 2012b, 2013; Zhang et al., 2013) to fit the four complex impedance tensor components for the 101 sites (two inversion with two models) that provided data of acceptable quality. For L1, the model domain had total dimensions $1160 \mathrm{~km} * 160 \mathrm{~km} * 400$ 
$\mathrm{km}$, consisting of a horizontal grid of 11 cells in the Xdirection (Perpendicular to L1) and 80 cells in the Y-direction (parallel to L1). Nominal grid spacing in the central part of the domain was approximately $0.5-3 \mathrm{~km}$. Vertically, the mesh had 40 layers, plus additional layers for the air. The prior model half-space was $100 \Omega \cdot \mathrm{m}$. Impedances for all 135 frequencies from 0.003 to $320 \mathrm{~Hz}$ were selected for inversion. Different frequencies were used at some sites because of the different processing methods. The regularization factor was set at 1 for the inversion to balance data misfit and model roughness. The root-mean-square deviation (RMSD) of data misfit was less than \pm 1.7 for all sites for the final iteration of the inversion. The serial inversion code required about $4 \mathrm{~h}$ for all computations on a single-processor PC with $4 \mathrm{CPU}(2.67$ $\mathrm{GHz}$ ) using essentially $1.04 \mathrm{~Gb}$ RAM.

The slice of 3D inversion model using L1 data is shown in Fig.2. The 3D inversion model using $\mathrm{L} 1$ and $\mathrm{L} 2$ data is shown in Fig. 3.

\section{DiscUSSION}

Figure 2 shows the deep electrical structure of L1, and two main sections were divided by the low resistivity body location in $110-125 \mathrm{~km}$. In the west part, one big high resistivity body (layer) with uplift shape was intrusive and segmented by three main low resistivity bodies (maybe connect in deep) located in $5-25,45-60$ and $80-100 \mathrm{~km}$. We consider the big high resistivity body is the big rock mass that was influenced by the upper mantle uplift for the formation of a shape before stage of Yanshan, and then was affected by the role of the transformation of the magma through about three channels (the three low resistivity bodies). In the east part, one big low and high resistivity bodies existed from west to east. We consider the conductor was theprimary fault structure formed before the stage of Yanshan, and the east high resistivity body is another big mass.

Figure 3 shows the deep electrical structure of part of L1 and L2. The surface is main low resistivity layer, including sedimentary strata, weathered strata and superficial Quaternary overburden, and it is about $0.3-0.4 \mathrm{~km}$ depth and its resistivity is less than $100 \Omega \cdot \mathrm{m}$. The deeper high resistivity $(>300 \Omega \cdot \mathrm{m})$ bodies are thermal metamorphic rock and intrusive rock mass.The basement is intrusion and alteration zone and sedimentary formation with resistivity of $160-600 \Omega \cdot \mathrm{m}$.

North section (shown in Figure 3b: part of L1) consists of three electric layer, three fracture units and superficial Quaternary and magmatic rockoverburden with low resistivity because of the weathering, and the Mesozoic volcanic rocks is below the cover with medium conductivity.

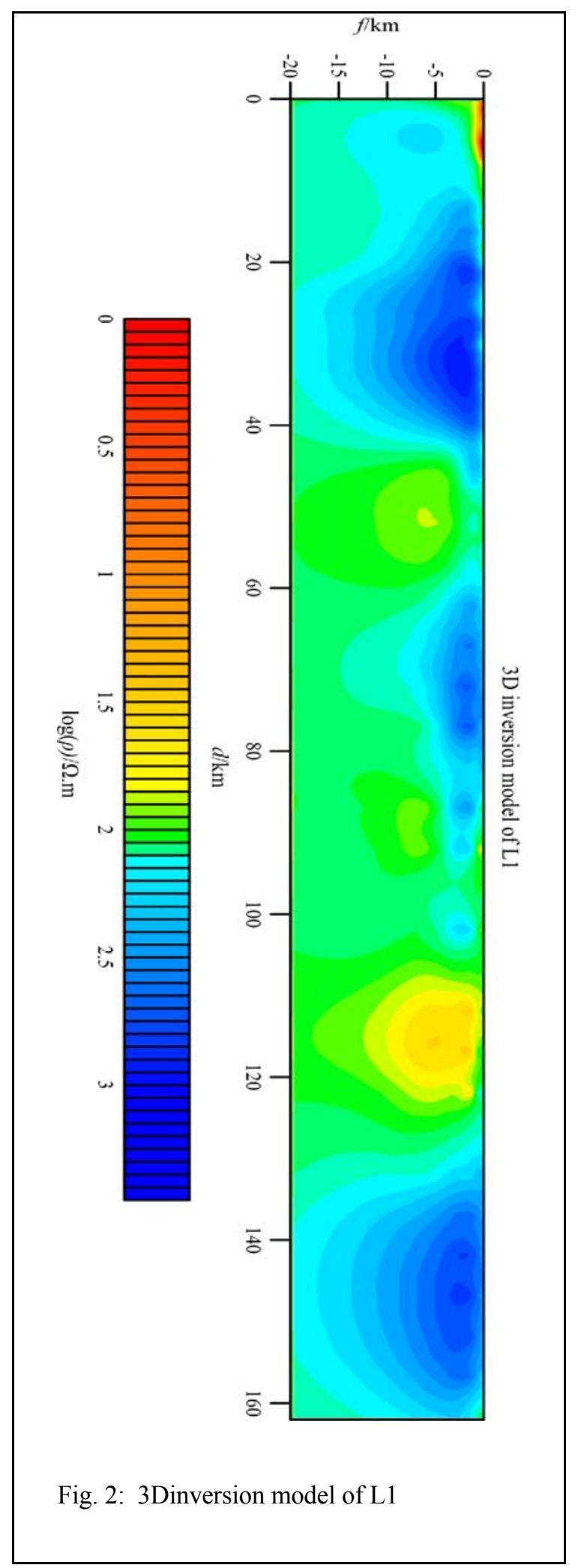


The deep layer is mainly consisted by Archean Proterozoic metamorphic rocks and the rock masses formed in the stage of Indo and Yanshan. Because of the sameelectrical conductivityof rock masses and metamorphic rocks, and the frequent interactions of magmatic and metamorphic rocks in the period of tectonic movement, the difference of electrical properties is very small in rock massed and metamorphic rocks. We consider that the basal is a conductor layer in the center lower crust, and the center uplift location is in the deep of Yidao fault (f1), and it is one of magma channel. And we consider there are three main fault structural belts, Yidao fault (f1), west part of Zhao - Ping fault (f2), east part of Zhao Ping fault (f3).Yidaois a stretching fault beltformed after the deep tectonic thermal uplift which pierced through the high resistivity layer of metamorphic and intrusive rocks, and its dip is northwestwith a characteristic of angle variation from shallow steep to deep gentle. The electrical difference of Zhao Ping fault and surrounding rock is small, so we consider it is a compression faultaffected by the late tectonic movement.

The South section mainly consists of four electric layers and two fracture units and mainly coveredby weathering low resistivity layer, and the Mesozoic volcanic rocks is below the surface conductor layer. The deep high resistivity layer is consisted by metamorphic rock and rock mass with low electrical difference. The basal is a conductor layer in the lower crust, and there are two main fault structural belts, Jiaojia fault (f4) and Yidao fault (f5). Yidao fault is the same as north section. Jiaojia fault is on the metamorphism and intrusive rock layer, and its dip is northwestwith a characteristic of angle variation from shallow steep to deep gentle. One low resistivity sedimentary basin is on the fault, and we consider it was a fault basin produced by extensional tectonics. And it is a basis to determine the sequence of tectonic movement.

\section{CONCLUSIONS}

We obtain the deep electrical structure in Jiaodong area base on the MT data in two profiles and their 3D inversion model. Then we find that a upper crust high resistivity layer and a center - lower crust conductor layer were existed in the area. And about two tectonic units existed in Jiaodong area with some secondary structural units in the west part. Then we discuss the main structure distribution and speculate the formation time of major geological structures.

\section{ACKNOWLEDGMENT}

The study is supported by the geological survey project" Integration of prospecting and exploration technology for deep ore prospecting of fractured altered rock type gold deposit" and the help of work group.

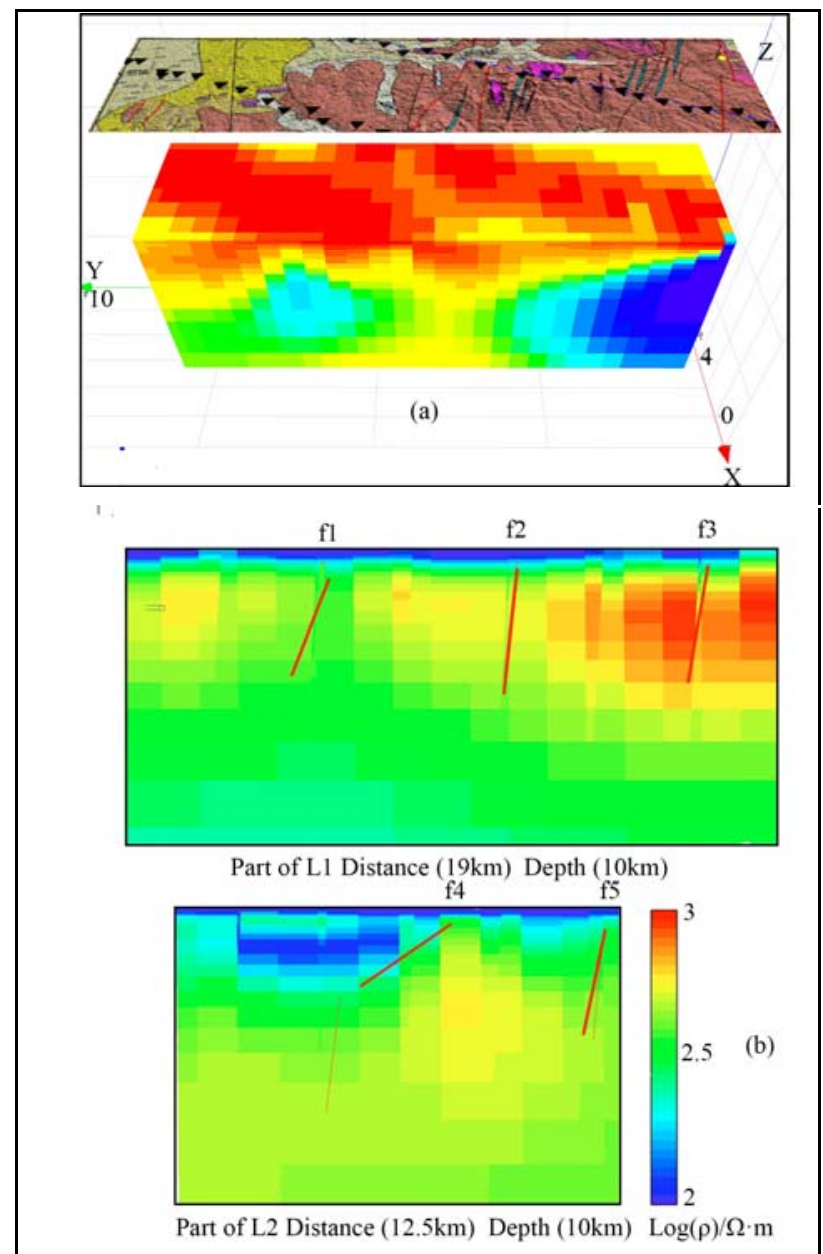

Fig.3 3Dinversion model of part of L1 and L2 (Zhang et al., 2015). (a): 3D inversion aera and model;(b): Slices of inversion model

\section{REFERENCES}

[1] J. Deng, Y.M. Chen., and Q. Liu, "The exploration of gold metallogenic system and resources of JiaodongSanshandao fault belt," Geological Publishing House. Beijing, pp. 1-371.

[2] J.Y. Yan, J.W. Teng, Q.T. Lu, "Geophysical exploration and application of deep metal mineral resources," Progress in Geophysics ProgGeophys. vol. 23, pp.871-891, March 2008.

[3] K. Zhang, W.B. Wei, Q.T. Lu, "Four changes for efficiency and practicality on previous 3D MT NLCG inversion algorithm," ActaGeodaetica et Geophysica. vol. 49, pp.551-563, March 2014.

[4] M.C. Song, S.X. Cui, P.H. Yi, "The deep and large scale of the northwest gold concentration area in the northwest of China: the prospecting and metallogenic model of the super large gold deposit," Geological Publishing House. Beijing, pp. 1-340. 